\section{Student Integration into STEM Careers and Culture: A Longitudinal Examination of Summer Faculty Mentors and Project Ownership}

\author{
Paul R. Hernandez, ${ }^{* *}$ Patricia D. Hopkins, ${ }^{\ddagger}$ Krysta Masters, ${ }^{\ddagger}$ Lisa Holland, ${ }^{\S}$ \\ Betty M. Mei," Michelle Richards-Babb, ${ }^{\S}$ Kimberly Quedado, " and \\ Natalie J. Shook ${ }^{\ddagger}$ \\ ${ }^{\dagger}$ Department of Learning Sciences and Human Development, " Psychology Department, \\ ${ }^{\circledR}$ Chemistry Department, "Office of the Provost, and "Office of Undergraduate Research, \\ West Virginia University, Morgantown, WV 26506-6212
}

\begin{abstract}
It is widely recognized that the United States needs to attract and retain more people in science, technology, engineering, and mathematics (STEM) careers. Intensive undergraduate research experiences (UREs) are one of the few strategies shown to improve longitudinal student interest and persistence in STEM-related career pathways; however, less is known about the underlying process linking activities to positive outcomes. The tripartite integration model of social influences (TIMSI) provides a framework for understanding the social influence processes by which students integrate into STEM careers and culture. The current study used a longitudinal design and latent growth curve modeling to examine and predict the development of scientific research career persistence intentions over the course of an intensive summer URE. The latent growth curve analysis showed that student persistence intentions declined and rebounded over the course of the summer. Furthermore, the positive impact of faculty mentor role modeling on growth trajectories was mediated through internalization of science community values. In addition, project ownership was found to buffer students from the typical trend of declining and rebounding persistence intentions. The TIMSI framework illuminates the contextual features and underlying psychological processes that link UREs to student integration into STEM careers and culture.
\end{abstract}

\section{INTRODUCTION}

It is widely recognized that the United States needs to attract and retain more people in science, technology, engineering, and mathematics (STEM) careers in order to drive innovation and broaden economic prosperity (National Academy of Sciences, National Academy of Engineering, and Institute of Medicine [NAS et al.], 2007; Holdren and Lander, 2012). At the undergraduate level, national statistics show high attrition from STEM majors and career paths ( $50 \%$; Hurtado et al., 2009; Chen, 2013; Olson and Riordan, 2012). Even among high-achieving STEM majors, longitudinal evidence indicates that student aspirations to pursue STEM-related research careers lessen as they advance toward graduation (Schultz et al., 2011). Although stakeholders and researchers have begun to identify a variety of promising curricular and cocurricular strategies to support student persistence in STEM (e.g., learning communities, inquiry-based curriculum; Russell et al., 2007; Kuh, 2008; Graham et al., 2013; Estrada et al., 2016), undergraduate research experiences (UREs) are one of the few strategies shown to improve longitudinal interest in STEM-related careers and persistence rates (Nagda et al., 1998; Hathaway et al., 2002; Russell et al., 2007; Schultz et al., 2011; Eagan et al., 2013; Rodenbusch et al., 2016; National Academies of Sciences, Engineering, and Medicine [NASEM], 2017; Hernandez et al., 2018). Thus, engaging students in
Erin L. Dolan Monitoring Editor

Submitted February 20, 2018; Revised May 15, 2018; Accepted May 15, 2018

CBE Life Sci Educ September 1, 2018 17:ar50

DOI:10.1187/cbe.18-02-0022

*Address correspondence to: Paul R. Hernandez (prhernandez@mail.wvu.edu).

(c) 2018 P. R. Hernandez et al. CBE-Life Sciences Education @ 2018 The American Society for Cell Biology. This article is distributed by The American Society for Cell Biology under license from the author(s). It is available to the public under an Attribution-Noncommercial-Share Alike 3.0 Unported Creative Commons License (http://creativecommons.org/licenses/ by-nc-sa/3.0).

"ASCB $\AA^{\prime}$ " and "The American Society for Cell Biology $®$ " are registered trademarks of The American Society for Cell Biology. 
authentic UREs has become a cornerstone of individual and institutional efforts to improve learning and persistence in STEM (Lopatto, 2003; Russell et al., 2007; Laursen et al., 2010; Linn et al., 2015; Mervis, 2016; NASEM, 2017). Despite growing evidence of the effectiveness of UREs, less is known about the key contextual features of these experiences and the psychological factors that explain how, why, and for whom UREs enhance interest and persistence (NASEM, 2017). Therefore, the current study examined the influence of key contextual features (e.g., faculty mentor psychosocial support) and psychological factors (e.g., scientific identity) that are hypothesized to influence the longitudinal growth of STEM career persistence intentions.

\section{Characteristics and Benefits of UREs}

Undergraduate research experiences vary widely in their goals and contextual features (e.g., targeted student population [lower division vs. upper division], duration [number of months or semesters], intensity [number of hours per week], level of project ownership and independence, timing [academic year vs. summer], structure [traditional faculty apprenticeship vs. course based]; Seymour et al., 2004; Auchincloss et al., 2014; Linn et al., 2015; NASEM, 2017). However, the common themes that define UREs concern engaging students in authentic scientific practices and in discovery that is of interest to the larger scientific community (Seymour et al., 2004; Sadler et al., 2010; Auchincloss et al., 2014; NASEM, 2017). UREs that engage students in authentic practices and discovery are associated with diverse benefits for learning (e.g., deeper conceptual understanding) and higher rates of persistence in STEM majors and career pursuits (Lopatto, 2004, 2007; Russell et al., 2007; Schultz et al., 2011; Thiry et al., 2012; Eagan et al., 2013; Graham et al., 2013; Linn et al., 2015; NASEM, 2017; Hernandez et al., 2018).

Longitudinal experimental and quasi-experimental studies have shown that, compared with peers without research experiences, undergraduates who engage in apprenticeship-style faculty-mentored UREs are significantly more likely to maintain higher aspirations for scientific careers, graduate with STEM baccalaureate degrees, enroll in STEM-related graduate programs, and engage in postbaccalaureate STEM-related careers (Nagda et al., 1998; Hathaway et al., 2002; Schultz et al., 2011; Eagan et al., 2013; Hernandez et al., 2018). The benefits of UREs are particularly pronounced for students who engage in multiple high-intensity (10+ hours per week) experiences, such as intensive summer research programs (e.g., National Science Foundation-funded Research Experience for Undergraduates [NSF REU]; Hernandez et al., 2018). The present study focused on apprenticeship-style faculty-mentored UREs in the context of an intensive summer research experience (i.e., typically 40 hours per week for 8 weeks).

There is a growing list of contextual features of UREs associated with beneficial outcomes (Hunter et al., 2007; Lopatto, 2007; Sadler et al., 2010; Thiry et al., 2011, 2012); however, mentorship support and project ownership are increasingly seen as essential for enhancing student interest and persistence in STEM career pathways (Lopatto, 2003; Pfund et al., 2006, 2016; Hanauer et al., 2012; Hanauer and Dolan, 2014; Hernandez et al., 2016; NASEM, 2017). Although definitions of mentorship vary, in undergraduate contexts, "mentorship" can be defined as a developmental relationship between a more experienced person (mentor) and a less experienced person (protégé), wherein the mentor provides support to enhance the protégé's professional development and integration into the field (Jacobi, 1991; Eby et al., 2007; Crisp and Cruz, 2009). Studies of facultystudent mentoring relationships have shown that support can be operationalized in a variety of ways: psychosocial support (e.g., counseling), instrumental support (e.g., providing opportunities for skill development, learning, and advancement), role modeling (e.g., providing inspiration by being a relevant and attainable example of success), coauthoring experiences (e.g., collaborative presentations or publications), and overall relationship satisfaction (Jacobi, 1991; Lockwood and Kunda, 1997; Paglis et al., 2006; Eby et al., 2013; Hernandez et al., 2016; Pfund et al., 2016). Project ownership has been broadly defined as student perceptions of agency, personal responsibility, and commitment to and identification with a project (Hanauer et al., 2012). A recent linguistic analysis of undergraduate STEM students' discussions of their research projects revealed that project ownership entailed making connections between scientific inquiry and personal history, agency (i.e., support seeking) and mentorship, excitement toward inquiry, overcoming challenges, and expressions of satisfaction with personal scientific achievement (Hanauer et al., 2012; Hanauer and Dolan, 2014). Both mentorship support and project ownership have been associated with beneficial outcomes, such as gains in science identity and persistence intentions (Hanauer and Dolan, 2014; Linn et al., 2015; Estrada et al., 2018).

The benefit of engaging in UREs is increasingly clear; however, the developmental processes that link UREs and contextual features to persistence outcomes is not well understood (NASEM, 2017). This gap in the literature is due, in part, to the fact that much of the URE literature has been focused on effectiveness rather than process. More specifically, much of the extant literature has focused on changes in outcomes measured at the end or long after the URE, rather than on the developmental processes that occur within the context of the URE (Lopatto, 2007; Adedokun et al., 2014; Fakayode et al., 2014; Fuchs et al., 2016; Hernandez et al., 2018). Furthermore, social science theories of motivation and persistence have only recently begun to inform and describe the developmental processes linking URE activities to beneficial outcomes through changes in psychological processes (Lent et al., 1994; Estrada et al., 2011; Graham et al., 2013; Wang and Degol, 2013; NASEM, 2017). A theory-driven and developmental processfocused approach can extend our understanding of the underlying psychological processes linking activities to outcomes.

\section{Developmental Process of Integrating into STEM Careers and Culture}

The tripartite integration model of social influences (TIMSI) describes the developmental process by which students integrate into STEM careers and culture (Estrada et al., 2011, 2018). TIMSI extends Kelman's social influence theory of how individuals socialize into social groups (or systems) to STEM careers and culture (Kelman, 2006; Estrada et al., 2011). Kelman's social influence theory posits that individuals socialize into a group through three distinct processes: compliance (i.e., adhering to rules and norms to garner rewards and avoid punishment), identification (i.e., constructing a social identity that 
incorporates the activities of the group), or internalization (i.e., adopting and sharing the values of the group; Kelman, 2006). The TIMSI model operationalizes these processes in terms of science efficacy, science identity, and internalizing scientific community values, respectively (Estrada et al., 2011). Science efficacy describes individuals' confidence that they can successfully execute scientific practices and thereby receive rewards in academic settings (Bandura, 1977; Estrada et al., 2011). Science identity describes the degree to which individuals see themselves as scientists, that is, the psychological centrality of the scientist social identity (Chemers et al., 2011; Estrada et al., 2011). Internalization of science community values represents the degree to which individuals authentically value the objectives of the scientific community (e.g., scientific discovery; Estrada et al., 2011). The process of socializing into a group develops over time, and thus, the social influence and integration processes need to be measured over time.

Faculty-mentored research experiences can function as influence agents to integrate students into STEM careers and culture (Estrada et al., 2011, 2018; Hernandez et al., 2016). That is, UREs and mentors can draw students into STEM careers and culture through the provision of experiences and support that encourage students to internalize the norms, behaviors, attitudes, identity, and values of the scientific community (Bauer and Green, 1994; Thiry and Laursen, 2011; Kardash and Edwards, 2012; Woodcock et al., 2015). A preponderance of empirical research has shown positive associations between science self-efficacy, science identity, scientific community values, and STEM persistence (Byars-Winston et al., 2010; Chemers et al., 2011; Estrada et al., 2011, 2018; Graham et al., 2013; Merolla and Serpe, 2013; Robnett et al., 2015). Among studies that included all three social influence processes, evidence typically shows that science identity and science community values uniquely predict persistence (Estrada et al., 2011, 2018; Hanauer et al., 2016). However, little empirical research

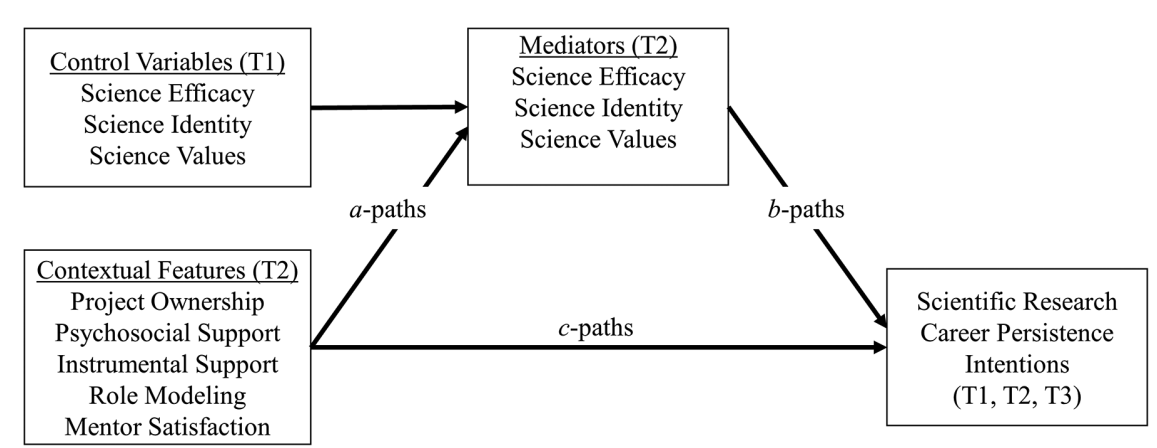

FIGURE 1. Conceptual model relating mentor supports and project ownership to scientific career persistence intentions through changes in scientific efficacy, science identity, and science community values. a-paths: the effect of mentor supports and project ownership (contextual features) on science efficacy, identity, and values (mediators), controlling for initial levels of science efficacy, identity, and values; $b$-paths: the effects of the science efficacy, identity, and values on the growth in science career persistence intentions (outcome), controlling for mentor support and project ownership; $a b$ : the effects of mentorship and project ownership on growth in science career persistence intentions through their impact on science efficacy, identity, and values (not shown); and c-paths: the effects of mentorship and project ownership on growth in science career persistence intentions, controlling for science efficacy, identity, and values; T1: measurement occurred at time 1 (typically week 1 of 8), T2: measurement occurred at time 2 (typically week 4 of 8), T3: measurement occurred at time 3 (typically week 8 of 8 ). has examined the impact of URE contextual features on STEM persistence through changes in science efficacy, science identity, processes or mediators, Estrada et al., 2018). To date, one study laureate persistence in a STEM career, finding that the impact of mentorship was mediated through science identity (Estrada al., 2018). Research questions and hypotheses about the social influence processes of science efficacy, identity, and

\section{Current Study}

The current study was designed to examine the processes by the extant reser. Specifically, the current study used longitdinal design within the context of intensive summer UREs (SUREs) to measure changes in STEM career persistence intenions over the course of the experience. In addition, the current che psychologiintegration into STEM careers and culture (i.e., persistence intentions). The present study addresses the following TIMSI-informed research questions and hypotheses.

1. How do scientific research career persistence intentions change over the course of an intensive summer research experience (i.e., times 1,2 , and 3 )? ( community values (measured at time 2) predict final scientions (time 3) and growth in persistence intentions? On the basis of TIMSI, we hypothesized that faculty mentorship support, project ownership, science self-efficacy, science identity, and science community values would all be positively correlated with scientific research career persistence intentions.

3. To what degree are the effects of faculty mentorship support and project ownership on scientific persistence intentions mediated through science self-efficacy, science identity, or science community values (controlling for initial levels of efficacy, identity, and values)? On the basis of TIMSI, and as shown in Figure 1 ( $a$ paths), we hypothesized that faculty mentorship support and project ownership would positively predict the TIMSI social influence processes (i.e., mediators) of science self-efficacy, identity, and community values over and above baseline levels of each (i.e., predict changes in efficacy, identity, and values). Furthermore, as shown in Figure 1 $(a \times b$ mediated effect), we hypothesized 
that the positive effect of faculty mentorship support and project ownership on scientific career persistence intentions would be mediated through identity and values.

\section{METHODS}

\section{Participants and Procedures}

Two hundred three undergraduate students at a U.S. university participated in the study (59.6\% female; median age $=20$ years; 4.9\% African American, 8.9\% Asian, 2.5\% Hispanic, $71.9 \%$ white non-Hispanic, $11.8 \%$ other). Most participants were students of the host institution (87\%), and most were either rising seniors or rising juniors (47.8 and 37.4\%, respectively). Students self-reported majoring in a variety of STEM disciplines across the life sciences (e.g., animal science, biology, immunology, neuroscience; 36\%), physical sciences (e.g., chemistry, geology, physics; 29\%), social sciences (e.g., psychology, political science; 8\%), and computer science and engineering (e.g., aerospace, mechanical; 27\%).

Participants were in the following programs for their summer research experience: a Cancer Institute research experience (2.5\%), a McNair summer research experience (9.9\%), NSF REUs for Nanotechnology (12.3\%) and Chemistry 9.9\%), a state-funded SURE (55.5\%), or a local summer undergraduate research internship (10.3\%). All programs provided financial support in the form of a stipend. However, the programs varied (slightly) in terms of their length (8-10 weeks) and in the types and intensity of supports they provided for student research experiences. Each program offered some degree of support for team-building activities, mentoring workshops and support from program managers, networking events, and scientific communication opportunities (e.g., communication training and judged poster presentations). For example, the REU Nanotechnology program emphasized accountability of research progress through weekly group meetings facilitated by Web conferencing. Other programs, such as SURE, offered participants a variety of opportunities for specific trainings (e.g., responsible conduct of research, scientific search engines) and career mentoring seminars.

Students were assessed at the beginning, midway, and end of their SURE (approximately weeks 1, 4, and 8 of the summer experience). Questionnaires were administered when students attended group meetings for their respective programs. At each time point, participants completed paper-and-pencil questionnaires that assessed the quality and characteristics of their research and mentoring experiences with their faculty mentors (e.g., project ownership, psychosocial support), science career persistence intentions, science self-efficacy, science identity, science community values, and demographics. Participants also completed several measures unrelated to the current study (e.g., university belonging). Participation was voluntary, and participants did not receive any compensation. All procedures were approved by the local university's institutional review board.

\section{Measures \\ Outcome}

Scientific career persistence intentions (Woodcock et al., 2015): This is a two-item scale that measures student intent to pursue a science career. Participants responded to the following items: "To what extent do you plan to pursue a science-related graduate degree?" and "What is the likelihood of you obtaining a science-related undergraduate degree?" on a scale from 1 (definitely will not) to 10 (definitely will). A composite score was created by averaging all items together, such that higher scores indicated greater intent to pursue a science career.

\section{Social Influence Processes (Mediators)}

Science self-efficacy (Chemers et al., 2011): This is a fiveitem scale that assesses confidence and abilities to function as a scientist. Participants rated their confidence that they could complete a series of scientific tasks (e.g., "Use technical science skills"; the complete list of items is provided in the Supplemental Material) on a scale from 1 (not at all confident) to 5 (absolutely confident). A composite score was created by averaging all items together, such that higher scores indicated greater science self-efficacy.

Science identity (Chemers et al., 2011): This is a three-item scale that assesses the extent to which individuals think of themselves as scientists. Participants responded to the items (e.g., "I have come to think of myself as a scientist"; the complete list of items is provided in the Supplemental Material) on a scale from 1 (strongly disagree) to 5 (strongly agree). A composite score was created by averaging all items together, such that higher scores indicated greater science identity.

Science community values (Estrada et al., 2011): This is a four-item scale that assesses the extent to which individuals value science. Participants rated the degree to which statements were like themselves (e.g., "A person who thinks discussing new theories and ideas between scientists is important"; the complete list of items is provided in the Supplemental Material) on a scale from 1 (not at all like me) to 5 (very much like me). A composite score was created by averaging all items together, such that higher scores indicated greater science values.

\section{URE Contextual Features}

Faculty mentorship role modeling (Hoyt et al., 2012):. This four-item scale was adapted to the current summer research context to assess the extent to which individuals identified their faculty mentor as a role model (e.g., "I identify with the life of my mentor"). Participants responded to items on a scale from 1 (strongly disagree) to 5 (strongly agree). A composite score was created by averaging all items together, such that higher scores indicated identification of their faculty mentor as a role model.

Faculty mentorship satisfaction (Ensher and Murphy, 1997): This three-item scale assesses the extent to which individuals were satisfied with their faculty mentoring relationship (e.g., "My mentor met my expectations"; the complete list of items is provided in the Supplemental Material). Participants responded to items on a scale from 1 (strongly disagree) to 5 (strongly agree). A composite score was created by averaging all items together, such that higher scores indicated greater satisfaction with the faculty mentoring relationship. 
Faculty psychosocial and instrumental mentorship support (Dreher and Ash, 1990; Hernandez et al., 2016): The faculty mentorship psychosocial support subscale consisted of four items (e.g., "To what extent has your mentor encouraged you to talk openly about anxieties and fears?"), while the instrumental support subscale consisted of six items (e.g., "To what extent has your mentor helped you improve your writing skills?"; the complete list of items is provided in the Supplemental Material). Participants responded to the items on a scale from 1 (not at all) to 5 (a very large extent). The items were averaged together to create subscales scores; higher scores indicated greater faculty mentor psychosocial or instrumental support.

Project ownership (I. Hernandez and A. Woodcock, personal communication): This nine-item scale assesses the extent to which individuals perceive ownership of and independence in the conduct of their research project (i.e., "Was I in control of my research project?"). This scale emphasizes the agency and mentorship facets of the ownership construct (a complete list of item contents is provided in the Supplemental Material). Participants responded to items on a scale from 1 (not at all) to 5 (to a very large extent). A composite score was created by averaging all items together, such that higher scores indicated greater ownership over the research project.

Demographics: Participants were also asked to provide demographic information (e.g., age, gender, URE program).

\section{Missing Data, Nesting, Statistical Assumptions, and Model Fit}

The response rate varied slightly across the three survey administrations; see Table 1. Descriptive analysis showed that $65.5 \%$ of participants completed all three surveys, $28.6 \%$ completed two surveys, and $5.9 \%$ completed one survey. Missing data analyses were conducted to identify the missing data mechanism (i.e., missing completely at random [MCAR], missing at random, or not missing at random; Enders, 2010, 2011). Little's MCAR test (Little, 1988) revealed that the data were missing completely at random, $\chi^{2}(73)=77.55, p=0.34$; therefore, our analysis plan proceeded using maximum-likelihood estimation without adjustments for missing data (e.g., auxiliary variables; Enders, 2010).

These data were collected from students nested within several different SURE programs (e.g., Cancer Institute). Nested data structures can violate the assumption of independent errors, as evidenced in intraclass correlations (ICCs), which results in biased model estimates (Raudenbush and Bryk, 2002). A preliminary analysis revealed that between 7 and $17 \%$ of the variability in scientific persistence intentions was accounted for by summer programs (i.e., $\mathrm{ICC}_{\text {time } 1}=0.07, \mathrm{ICC}_{\text {time } 2}$ $\left.=0.13, \mathrm{ICC}_{\text {time } 3}=0.17\right)$. Therefore, the nesting variable representing the six URE programs was recoded into a set of five dummy-coded variables and entered into all statistical models to control for nesting (Cohen et al., 2003). In addition, all continuous predictor and control variables were centered in substantive analyses.

Preliminary data screening, statistical assumption checking, and missing data analysis were conducted in SPSS v. 23. Outlier analysis using leverage values, Studentized deleted residuals, and Cook's $D$ values indicated no extreme outlier cases
(Judd et al., 2009). In addition, residual diagnostics indicated that the assumptions of linearity, normality of residuals, and homoscedasticity were met.

All subsequent data analyses were conducted in a structural equation modeling (SEM) framework using maximum-likelihood estimation in Mplus v. 7.4 (Muthén and Muthén, 19982017). The SEM framework offers distinct advantages over other multivariate statistical methods for assessing the fit of theoretically derived hypotheses to data. SEM allows the researcher to specify the conceptual or theoretical model and provides a variety of indicates that describe the adequacy of the model-data fit. The various indices of model-data fit allow researchers to evaluate the degree to which the data speak against the model (Kline, 2016). For example, the present study will test the model-data fit of our conceptual model (Figure 1), wherein the social influence processes and contextual features predict scientific persistence intentions over time. In addition, the SEM framework allows for direct comparisons of alternative (nested) models based on their model-data fit. For example, the present study will compare the model fit of the conceptual model versus an alternative (null) model, wherein the social influence processes and contextual features do not predict scientific persistence intentions over time.

Model fit was assessed using a variety of indices, including the chi-square goodness of fit test $\left(\chi^{2}\right)$, root-mean-square error of approximation (RMSEA; i.e., a parsimony index), the comparative fit index (CFI; i.e., an incremental index), and the standardized root-mean-square residual (SRMR; i.e., an absolute fit index). Consistent with current standards, we evaluated model fit indices relative to recommended cutoff values (Hu and Bentler, 1999): RMSEA values at or below 0.05 (or nonsignificant $p$-value for close fit $\left[p_{\text {Close }}\right]$ test), CFI values at or above 0.95, and SRMR values at or below 0.08 indicated good model-data fit.

Finally, we implemented a Bonferroni correction on the basis of the number of outcome variables in our models to evaluate the statistical significance of parameter estimates (alpha level $=$ $0.05 / 5=0.01$ ). We took this precaution to control the type I error rate, as it has been shown that large structural equation models with many parameters and exploratory analyses can inflate the type I error rate (Green and Babyak, 1997; Cribbie, 2000).

\section{RESULTS}

\section{Persistence Intentions Exhibit Quadratic Growth over Summer UREs}

Before testing hypotheses, we examined the descriptive statistics for changes in scientific career persistence intentions over time. The average level of persistence intentions declined from time $1(M=7.67)$ to time $2(M=7.46)$, then bounced back in time $3(\mathrm{M}=7.64)$. The pattern of decline followed by rebound indicated a quadratic growth trend, which we modeled in SEM.

Structural equation model 1 (SEM 1) was designed to formally address research question 1 (i.e., the degree to which persistence intentions change over the course of a summer research experience). We used latent growth curve analysis to model the pattern of decline followed by a rebound in scientific career persistence intentions over time (i.e., analysis of linear and quadratic growth trends), while statistically controlling for any potential differences across summer programs (i.e., controlling for nesting of students within programs). The results 


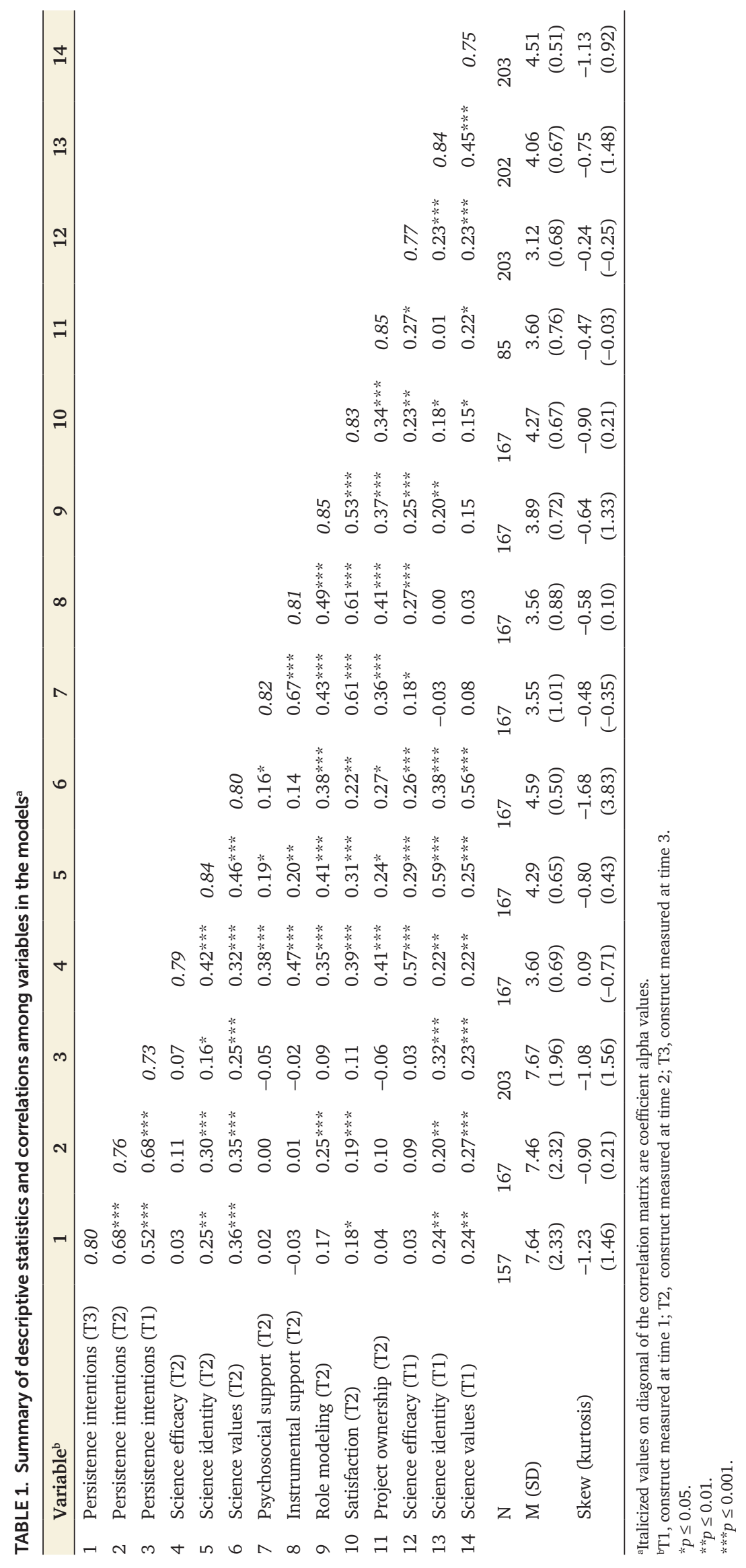




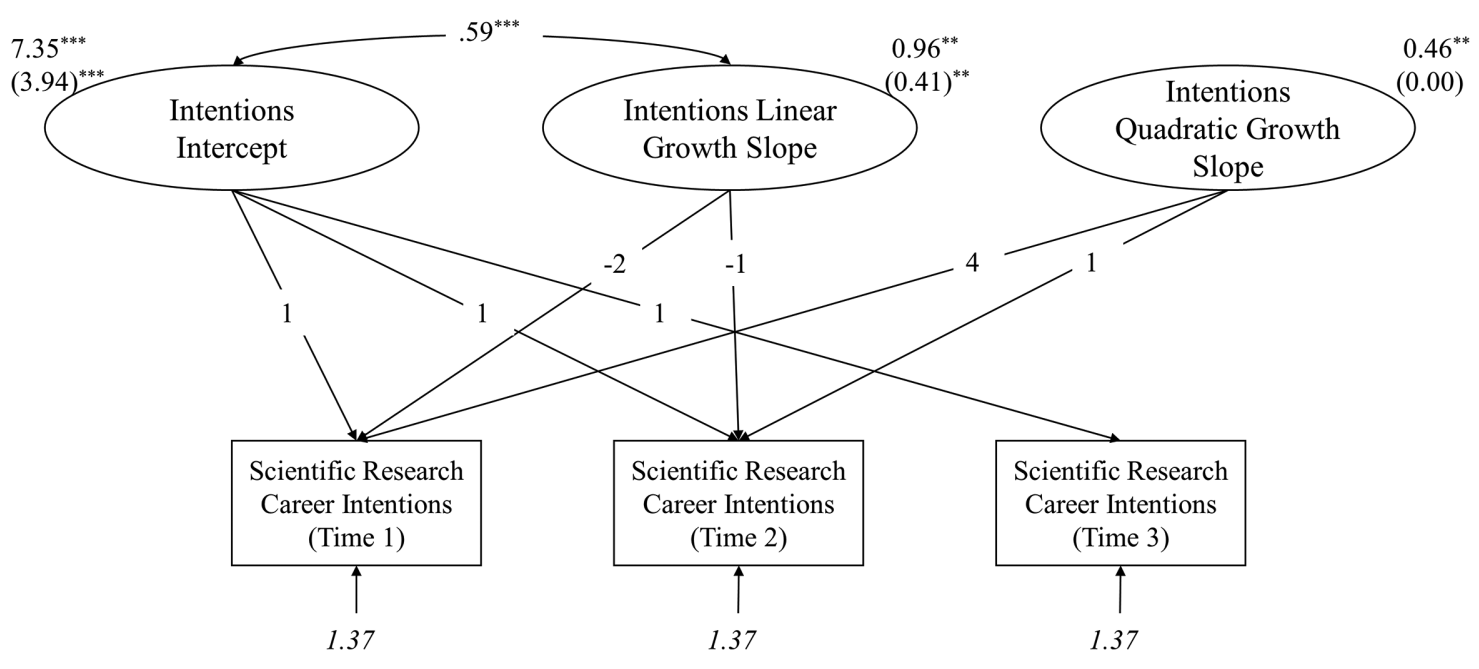

FIGURE 2. Results of the latent growth curve model of scientific research career peristence intentions (SEM 1). Values outside parentheses represent estimates of growth in science career persistence intentions (i.e., latent intercept $=7.35=$ average persistence intentions at time 3 ; linear slope $=0.96=$ decline in persistence intentions from time 1 to time 2 ; quadratic slope $=0.46=$ rebound in persistence intentions from time 2 to time 3); values inside parentheses represent variances of the estimate of growth in science career persistence intentions; italicized values represent residual variance in persistence intentions at each time point; and values on paths represent how time was coded to model growth over time in SEM. All other variables in the analysis were allowed to correlate with growth parameters but are not shown in this diagram for the sake of parsimony. ${ }^{* *}, p \leq 0.01 ; * * *, p \leq 0.001$.

showed that the model (SEM 1) adequately fitted the data, $\chi^{2}(69)=115.83, p<0.001$, RMSEA $=0.06, p_{\text {Close }}=0.23, \mathrm{CFI}=$ $0.95, \mathrm{SRMR}=0.06$.

The latent growth curve analysis formally tested the trends identified from the descriptive statistics. Consistent with the descriptive statistics, the latent growth curve revealed that students' persistence intentions exhibited a statistically significant decline from the beginning to the midpoint of the SURE (Figure 2 , Intentions Linear Growth Slope $=0.96$ ), followed by a statistically significant rebound from the midpoint to the end of summer (Figure 2, Intentions Quadratic Growth Slope = 0.46). By the end of the SURE, students reported persistence intentions had basically returned to where they were at time 1 (Figure 2, Intentions Intercept $=7.35$ on a $1-10$ scale). The analysis also revealed that students exhibited significant variability in how much their persistence intentions declined from time 1 to time 2 (Figure 2, Intentions Linear Growth Slope $=0.41$ ) and significant variability in their end of summer persistent intentions (Figure 2, Intentions Intercept $=3.94$ ).

\section{Scientific Community Values Influence Final Summer Persistence Intentions}

Next, we addressed research question 2 , concerning the predictive utility of scientific mediators and contextual features. We hypothesized that the scientific mediators and contextual features at time 2 would be significantly and positively correlated with persistence intentions at time 3 . Partially consistent with our hypothesis, students with higher levels of scientific identity, higher levels of scientific community values, higher satisfaction with their faculty mentors, and higher perceptions of their faculty mentors as role models also reported higher levels of persistence intentions (see Table 1). The bivariate correlations between persistence intentions at time 3 and some of the scientific mediators and contextual features at time 2 were small to moderate in magnitude using Cohen's proposed metrics for interpreting magnitude of correlations (i.e., small = 0.10 , medium $/$ moderate $=0.30$, large $=0.50$; Cohen, 1992) .

To formally test our research question about the predictive utility of the scientific mediators and contextual features, we compared the model-data fit of two additional nested structural equation models (i.e., SEM 2 and SEM 3). To begin, we tested the model-data fit of our conceptual model (Figure 1; SEM 2), which hypothesized that students' science self-efficacy, science identity, science community values (Figure 1, Mediators), experiences of faculty mentorship support, and project ownership at time 2 (Figure 1, Contextual features) would predict scientific career persistence intention at time 3 . The model fit statistics indicated that SEM 2 provided acceptable fit to the data, $\chi^{2}(73)$ $=121.56, p<0.001$, RMSEA $=0.06, p_{\text {Close }}=0.24, \mathrm{CFI}=0.91$, SRMR $=0.06$ (parameter estimates shown in Table 2). Next, we tested the model-data fit of a null model (SEM 3), which hypothesized that neither the mediators nor the contextual features would predict scientific career persistence intention (Figure $1, b$ paths and $c$ paths $=0$ ). If the null model (SEM 3) did not worsen model fit compared with the conceptual model (SEM 2), we could conclude that the scientific mediators and contextual features provide no predictive utility in explaining growth in persistence intentions. The model fit statistics indicated that the null model (SEM 3) did not provide acceptable fit to the data, $\chi^{2}(91)=161.43, p<0.001$, RMSEA $=0.06, p_{\text {close }}=0.11$, CFI $=$ 0.87, SRMR $=0.08$, and had significantly worse model fit compared with the conceptual model, $\Delta \chi^{2}(18)=39.87, p=0.002$. Consistent with our expectations, a comparison of the modeldata fit of the conceptual model versus the null model revealed that students' science self-efficacy, science identity, science community values, experiences of faculty mentorship support, and project ownership are important factors in explaining growth in scientific career persistence intention over time. 


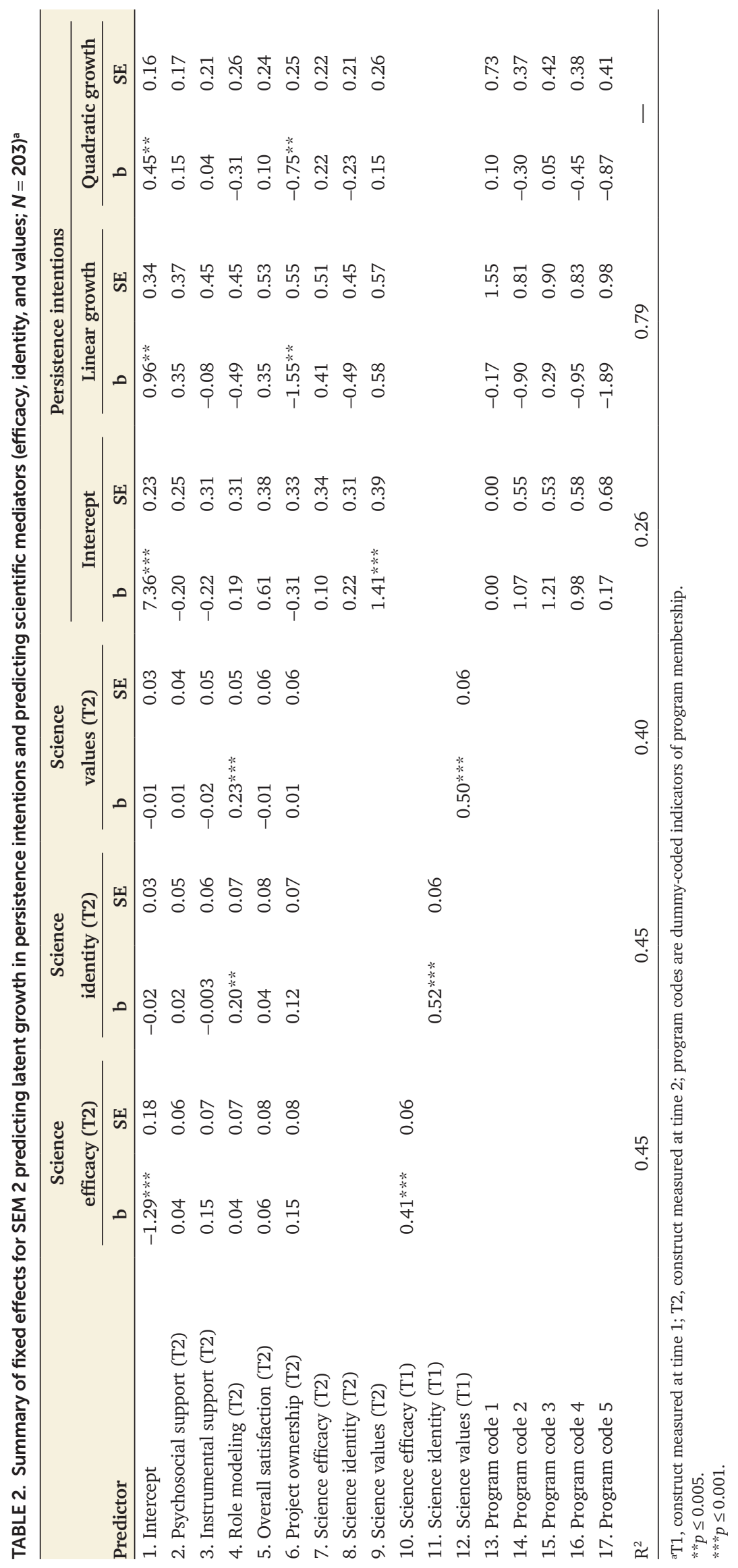


Our second hypothesis related to predictive utility was that science self-efficacy, identity, and community values would act as mediators and would be the only factors to significantly predict persistence intentions. If our hypothesis was accurate, the structural regression coefficients for science self-efficacy, identity, and community values would be positive and statistically significant, while the faculty mentoring and project ownership coefficients would be nonsignificant. We inspected the statistical significance of the structural regression coefficients to determine the pattern of uniquely predictive mediators and contextual features. Partially consistent with our hypothesis, students' internalization of scientific community values uniquely and positively predicted their end-of-summer scientific research career persistence intentions, when we controlled for the other predictors (Table 2, science community values predicts the intercept of persistence intention $b=1.41$ ). Inconsistent with our hypothesis, students' ownership of their projects directly affected the pattern of growth in their intentions to persist in science (Table 2; e.g., project ownership negatively predicts linear decline in persistence intentions $b=-1.55$ ). Figure 3 shows the growth trajectories for students of low, average, and high levels of project ownership. Higher levels of project ownership (dotted line) were associated with high and steady persistence intentions, whereas low levels of project ownership (solid line) were associated with the typical decline and rebound in persistence intentions. There were no significant differences between those with low, average, or high project ownership at either the beginning or end of the summer experience-only a difference in the growth trajectory (i.e., decline and rebound).

\section{Role Modeling Supports Persistence Intentions through Scientific Community Values}

Next, we addressed research question 3 (i.e., degree to which the quality of faculty mentorship and project ownership

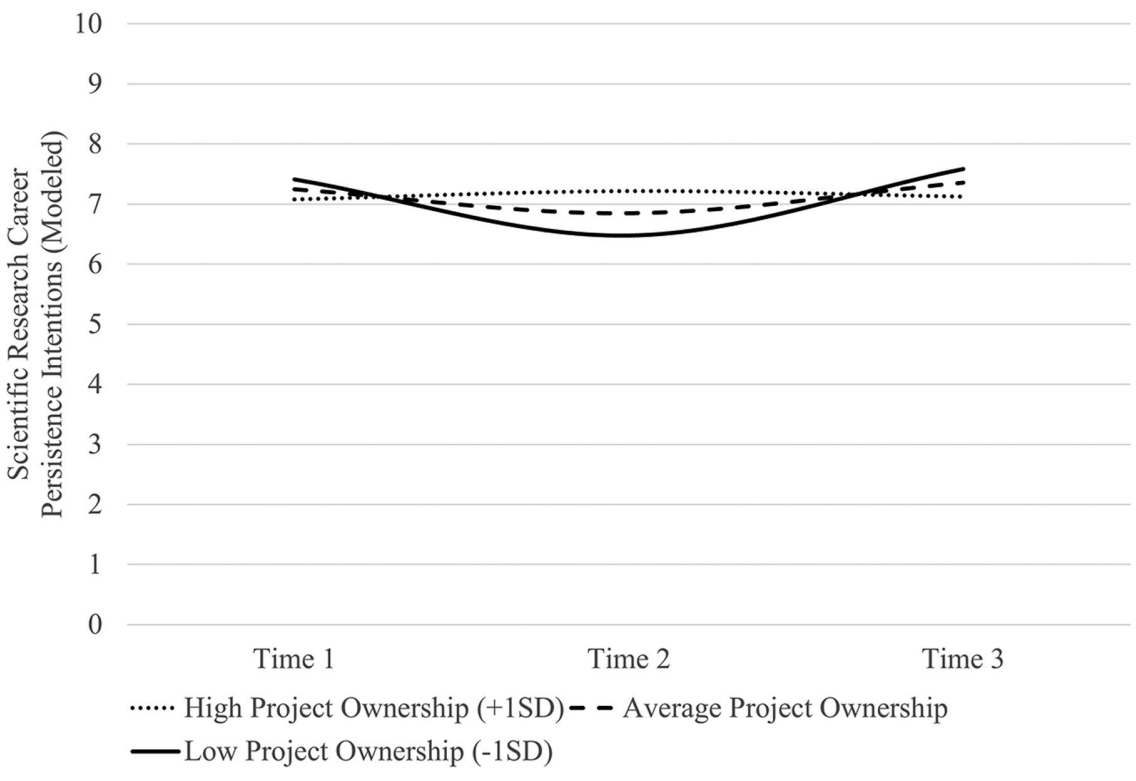

FIGURE 3. Project ownership predicts growth of scientific career persistence intentions. Growth trends modeled with project ownership at the average (i.e., mean of project ownership), below average (1 SD below average), and above average (1 SD above average). influences persistence intentions indirectly through scientific mediators). Consistent with expectations, the bivariate correlations showed that, at time 2 , students with higher levels of faculty mentorship support and higher levels of project ownership reported higher levels of science self-efficacy, science identity, and internalization of scientific community values (i.e., contextual features exhibited small-to-moderate bivariate correlations with the scientific mediators; Table 1).

However, we hypothesized that faculty mentorship support and project ownership would predict the scientific mediators over and above baseline levels of science self-efficacy, identity, and community values. To formally test our hypothesis, we compared the model-data fit of two additional nested structural equation models (i.e., SEM 2 and SEM 4). As described earlier, our conceptual model (SEM 2) hypothesized that the qualities of faculty mentorship support and project ownership would predict science self-efficacy, science identity, or science community values when controlling for baseline levels of the scientific mediators. Therefore, we tested the model-data fit of a null model (SEM 4), which hypothesized that neither the qualities of faculty mentorship support nor project ownership would predict science self-efficacy, science identity, or science community values (Figure 1 , a-paths $=0$ ). If the null model (SEM 4) did not worsen model fit compared with the conceptual model (SEM 2), we could conclude that the contextual features do not improve the prediction of the scientific mediators over and above baseline levels of the scientific mediators. The model fit statistics indicated that the null model (SEM 4) did not provide acceptable fit to the data, $\chi^{2}(88)=193.15, p<0.001$, RMSEA $=0.08, p_{\text {Close }}=0.002$, CFI $=0.81$, SRMR $=0.09$, and significantly worsened model fit compared with the conceptual model (SEM 2), $\Delta \chi^{2}(15)=71.59, p<0.001$. Consistent with our expectations, a comparison of the model-data fit revealed that students' experiences of faculty mentorship support and project ownership are important factors in explaining science self-efficacy, science identity, and science community values over and above their initial science self-efficacy, science identity, and science community values.

Our second mediational hypothesis was that faculty mentorship support and project ownership would increase students' scientific career persistence intentions, because those factors increased science identity and science community values. If our hypothesis was accurate, the various types of faculty mentorship support and project ownership would have statistically significant indirect effects on persistence intentions through science identity and community values. Partially consistent with our hypothesis, student perceptions of their faculty mentors as inspirational role models positively affected science identity and internalization of science community values (Table 2 ; e.g., role modeling predicts values (T2) $b=$ 0.23 ). Furthermore, students with higher levels of scientific community values had higher levels of scientific research career 


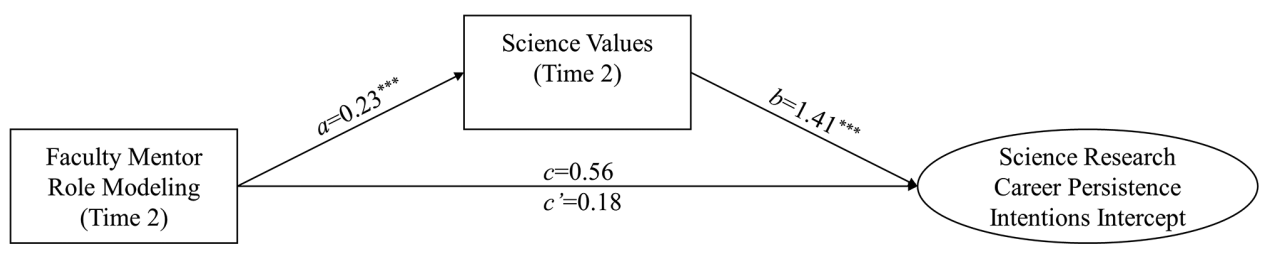

$a \times b=0.32$, bootstrapped $99 \%$ percentile $C I[0.05,0.68]$

FIGURE 4. Mediation model showing the positive effect of faculty mentor role modeling on science career persistence intentions at the end of summer through its positive influence on science community values. a-path: positive effect of faculty mentor role modeling on science community values (controlling for baseline levels of values); $b$-path: positive effect of science community values on science career persistence intentions at the end of summer (controlling for all other predictors in the model); c-path: total effect role modeling on persistence intentions (not controlling for other factors in the model); $c^{\prime}$-path: direct effect of role modeling on persistence intentions (controlling for all other factors in the model); $a \times b$ : indirect or mediated positive effect of faculty mentor role modeling on science career persistence intentions at the end of summer through its positive influence on science community values; nonsignificant paths and contrast-coded indicators of program not included in this diagram for the sake of parsimony. ${ }^{* * *}, p<0.001$.

persistence intentions at the end of the SURE. Consistent with best practices, we formally tested the statistical significance of the indirect effect of faculty role modeling on persistence intentions through scientific community values using a bootstrapping procedure with 10,000 repetitions to construct percentile confidence intervals around the mediated effect shown in Figure 4 (Shrout and Bolger, 2002; MacKinnon et al., 2007). The mediation analysis revealed that faculty role modeling had a statistically significant positive indirect effect on students' end-of-summer scientific research career persistence intentions through science community values (Figure 4, $a \times b=0.32$, and confidence intervals do not include 0 ).

\section{DISCUSSION}

The current study used a longitudinal design to measure developmental growth in students' scientific career persistence intentions over the course of a single intensive summer apprenticeship-style faculty-mentored research experience. In addition, the current study used the TIMSI model to examine the psychological processes that link URE activities to student integration into STEM careers and culture. Student growth trends over the summer did not conform to a simple narrative of continuous growth toward a scientific career. Rather, students' growth was more erratic, defined by declines and rebounds. Furthermore, faculty mentor support and student ownership over their research projects related to growth in science career persistence intentions differently. Project ownership directly supported growth in student aspirations to pursue scientific careers; however, faculty mentorship support operated in a more nuanced way. Faculty mentor support helped students to internalize scientific community values and to see themselves as "scientists," and these values and self-beliefs in turn galvanized their commitment to a scientific career.

A key finding from this research was that student intentions to pursue scientific careers declined and then rebounded over the course of the SURE (i.e., a quadratic developmental growth trend). This finding is novel, in part, because the SURE literature has relied heavily on posttest only or pre-post research designs to identify "gains" over the summer (e.g., Lopatto, 2004, 2007; Fuchs et al., 2016; Kolber et al., 2016). However, the posttest only and pre-post designs have many well-established methodological and statistical limitations to detect developmental processes or change over time via gain scores (Cronbach and Furby, 1970; Shadish et al., 2002; Maxwell and Delaney, 2004). Adding one or more intermediate measures between pretest and posttest allows researchers to detect and describe patterns of individual growth over time (Chan, 1998; Venter et al., 2002). In the present study, for example, it would have been impossible to document the drop in persistence intentions followed by a rebound in persistence intentions under a pre-post design. A simple gain score analysis (i.e., $\mathrm{M}_{\text {gain }}$ $=\mathrm{M}_{\text {posttest }}-\mathrm{M}_{\text {pretest }}=7.64-7.67=-0.03$; Table 1) would have revealed nothing about the pattern of growth that took place over the summer. Researchers interested in describing and explaining the role that research experiences play in developing the next generation of scientific professionals should strongly consider adding intermediate time points to their study design (at least one intermediate time point, but three intermediate time points would maximize statistical power; Maxwell, 1998; Venter et al., 2002).

The decline in persistence intentions from the first time point to the midpoint of summer was surprising and concerning, as one of the goals of SUREs is to promote scientific research careers. However, several factors may help to explain and mitigate the decline. It is possible that the social and interpersonal dynamics involved in transitioning into a new research lab with a new faculty mentor and lab coworkers caused turbulence that initially dampened students' interest in science careers. It is also possible that the first half of the SUREs involve particularly challenging and ambiguous aspects of authentic scientific research (e.g., reading background literature, defining a research problem with an unknown solution that is of interest to the scientific community, learning new protocols and equipment to carry out the research). In addition, authentic research is accompanied by setbacks, experiments that do not work as planned, equipment or instruments that break and hold up the experiment, and the need for supplies that have been ordered and have not yet arrived. Often students experience these setbacks in the middle of their project (time 2). Students new to research often do not realize that research is made up of lots of experiments that do not work but culminates in the one or two experiments that do work. The challenges and ambiguities in authentic research may initially dampen students' enthusiasm for scientific careers. By contrast, the second half of the SUREs 
may involve research processes that reinvigorate enthusiasm for scientific careers (e.g., gaining traction on discovery through iteration, mastery of new protocols and equipment, sharing research results at an end-of-summer poster presentation). Aspects of our findings hint at support for this explanation.

If challenges and ambiguity in research define the first half of the URE, then students with higher levels of research readiness should be better able to take ownership of their research projects and resolve the initial challenges. Prior research has shown that students engaged in challenging and ambiguous aspects of authentic research report lower project ownership than students engaged in more structured research projects with a known solution (i.e., research lab vs. traditional lab; Hanauer and Dolan, 2014). Consistent with this explanation, our data showed that students with high levels of science self-efficacy at the start of the SURE reported higher project ownership at the midpoint of the SURE $(r=0.27)$. Furthermore, students with high levels of project ownership at the midpoint of the SURE did not experience a drop in persistence intentions (Figure 3). Thus, students who begin the summer with higher levels of research readiness may be better prepared to take ownership of a project, resolve the challenges and ambiguity of the research project, and thus avoid the initial decline in their persistence intentions. More study is needed to substantiate this potential explanation for the initial decline in persistence intentions.

The beneficial effects of having high levels of project ownership also point to a potential area for intervention. That is, enacting policies and procedures that support students' project ownership may improve short-term outcomes (such as avoiding a decline in persistence intentions) and long-term persistence in scientific research careers (Hanauer et al., 2017). Any interventions aimed at supporting students' project ownership will need to be sensitive to the qualities that define ownership. Science students' perceptions of ownership are defined by five qualities: making connections between one's personal history and scientific inquiry; agency and mentorship; excitement; overcoming challenges; and expressions of personal scientific achievement (Hanauer et al., 2012; Hanauer and Dolan, 2014). Recent research has shown that the five elements of project ownership may be subsumed by two global factors of ownership defined by students' positive emotions toward the research project and their degree of agency over the research (Hanauer et al., 2017). Thus, interventions aimed at improving students' levels of project ownership should take into account students' sense of agency (task choice, personal sense of responsibility) and support in overcoming challenges, as well as emphasizing relevance of the project to the larger scientific community.

Another key finding from this study concerned the mechanisms by which faculty mentors draw students into science careers. Informed by the TIMSI model, we hypothesized that faculty mentorship support would support growth in persistence intentions through the development of science self-efficacy, science identity, and science community values (Figure 1; Estrada et al., 2011, 2018). However, the longitudinal TIMSI model revealed that faculty mentors primarily socialize students into science careers and culture through role modeling (as opposed to other types of mentorship support). That is, students who viewed their faculty mentors as more inspirational, in terms of identifying with a mentor's life and work, developed a stronger commitment to scientific community values-even after controlling for the students' levels of commitment to science community values at the start of the summer experience. This finding aligns with research showing that role models inspire aspirants by providing an example of the attitudes, norms, and behaviors required to achieve similar success (Lockwood et al., 2002). This finding also has implications for faculty mentors and URE programs, as the role modeling literature has identified several attributes of role modeling that promote inspiration, motivation, and persistence.

Role models are most effective and motivational when they are relevant (e.g., similar domain of shared interest [science career], similar gender), when their success is perceived to be attainable by identifiable pathways (Lockwood and Kunda, 1997, 1999; Lockwood et al., 2002; Lockwood, 2006), when they normalize struggle and promote effort to achieve success in STEM (Shin et al., 2016), and when they communicate that STEM careers are compatible with communal values (i.e., helping others; Clark et al., 2016). Therefore, we expect that faculty mentors who intentionally talk about their journeys into their scientific careers would be most likely to be inspirational role models (e.g., highlights from their personal histories: similarities they share with their mentees, where they started, how they achieved success, challenges they overcame through effortful development of new skills, how their work helps people). Therefore, faculty mentors and URE program organizers may wish to intentionally design conversations and activities that highlight the similarities between mentors and mentees, stress the relevance of the work to the mentees' future career aspirations, emphasize the pathways to attain similar success, normalize the struggle and the processes to overcome challenges, underscore the importance of effort (rather than brilliance) in achieving success, and demonstrate how their work helps people. These conversations and activities need not all come from the faculty mentor; conversations and activities may be equally influential coming from other potential role models who are slightly farther ahead of the mentee on the path to a scientific career-postdocs, graduate students, and even more advanced undergraduate researchers. For example, summer research coordinators for the present study are implementing activities such as the mentor biography and setting mentormentee expectations and research expectations to improve opportunities for role modeling and mentorship (Branchaw et al., 2010).

Although the present study addressed a number of theoretical and methodological gaps in the literature, there are limitations that require further study. For example, the present study focused on SURE participants enrolled in six distinct summer programs at one research-intensive university and used only self-reported measurements. Further study is needed to determine whether the same pattern of growth and stability of the effects on growth hold across multisemester or yearlong cocurricular or coursebased undergraduate research experiences. To date, other studies of course-based and cocurricular research experiences have not tracked developmental growth in persistence intentions within the bounds of the URE (Lopatto, 2007; Adedokun et al., 2014; Fakayode et al., 2014; Fuchs et al., 2016; Hernandez et al., 2018). In addition, limited evidence from one study that tracked science majors over three academic years showed a similar quadratic pattern in persistence intentions, one marked by an overall 
decline followed by a leveling off or slight rebound (Schultz et al., 2011). An additional limitation concerns the measurement of the outcome. Specifically, the current study operationalized persistence intentions in terms of students' aspirations to pursue a science career, while other studies have emphasized aspirations to pursue a research career. It is possible that this slight variation in focus on science versus research may have influenced some aspects of the findings. For example, prior work on the TIMSI model has shown that science identity, not science community values, was the most influential predictor of persistence intentions (Estrada et al., 2011, 2018). Further study will be needed to determine whether contextual features of the URE, the operationalization of persistence intentions, or other salient factors are the source of variability across the research literature. Related limitations concern the need to determine the degree to which these findings hold across a broader array of sources of mentorship support, types of summer programs, institutions, and methods of measurement. In particular, students involved in the current summer research programs likely received various types of support (psychosocial, instrumental, networking, etc.) from persons other than their faculty research mentors (program staff, graduate students, peers). More research is needed to better understand how support received from a network of mentors relates to beneficial outcomes. In addition, the present study only consisted of undergraduates engaged in a SURE. Further counterfactual evidence and evaluation of the TIMSI model would benefit from measuring the same processes in comparison samples of students engaged in low-intensity SUREs and among students not engaged in SUREs.

In summary, the present study was informed by the TIMSI model and addressed three research questions concerning changes in scientific career persistence intentions over time within a single intensive SURE. Our analysis showed that students tended to exhibit a swing (i.e., decline and rebound) in their persistence intentions over the course of the summer. However, students with high levels of project ownership exhibited steady persistence intentions, while those with lower project ownership experienced the downward and upward swing. Most importantly, the analysis revealed that faculty mentor role modeling increased students' internalization of science community values, and those values in turn increased students' scientific career persistence intentions.

\section{ACKNOWLEDGMENTS}

We gratefully acknowledge Heather Henderson and Rachel Henderson for their assistance collecting data.

\section{REFERENCES}

Adedokun, O. A., Parker, L. C., Childress, A., Burgess, W., Adams, R., Agnew, C. R., ... Teegarden, D. (2014). Effect of time on perceived gains from an undergraduate research program. CBE-Life Sciences Education, 13(1), 139-148. doi: 10.1187/cbe.13-03-0045

Auchincloss, L. C., Laursen, S. L., Branchaw, J. L., Eagan, K., Graham, M., Hanauer, D. I., ... Dolan, E. L. (2014). Assessment of course-based undergraduate research experiences: A meeting report. CBE-Life Sciences Education, 13(1), 29-40. doi: 10.1187/cbe.14-01-0004

Bandura, A. (1977). Self-efficacy: Toward a unifying theory of behavioral change. Psychological Review, 84(2), 191-215. doi: 10.1037/0033-295X 84.2.191

Bauer, T. N., \& Green, S. G. (1994). Effect of newcomer involvement in work-related activities: A longitudinal-study of socialization. Journal of Applied Psychology, 79(2), 211-223. doi: 10.1037//0021-9010.79.2.211
Branchaw, J., Pfund, C., \& Rediske, R. (2010). Entering research: Workshops for students beginning research in science. New York: Freeman.

Byars-Winston, A., Estrada, Y., Howard, C., Davis, D., \& Zalapa, J. (2010). Influence of social cognitive and ethnic variables on academic goals of underrepresented students in science and engineering: A multiple-groups analysis. Journal of Counseling Psychology, 57(2), 205-218. doi: 10.1037/ a0018608

Chan, D. (1998). The conceptualization and analysis of change over time: An integrative approach incorporating longitudinal mean and covariance structures analysis (LMACS) and multiple indicator latent growth modeling (MLGM). Organizational Research Methods, 1(4), 421-483. doi: 10.1177/109442819814004

Chemers, M. M., Zurbriggen, E. L., Syed, M., Goza, B. K., \& Bearman, S. (2011). The role of efficacy and identity in science career commitment among underrepresented minority students. Journal of Social Issues, 67(3), 469-491. doi: 10.1111/j.1540-4560.2011.01710.x

Chen, X. (2013). STEM attrition: College students' paths into and out of STEM Fields (NCES 2014-001). Washington, DC: National Center for Education Statistics, Institute of Education Sciences, U.S. Department of Education.

Clark, E. K., Fuesting, M. A., \& Diekman, A. B. (2016). Enhancing interest in science: Exemplars as cues to communal affordances of science. Journal of Applied Social Psychology, 46, 641-654. doi: 10.1111/jasp.12392

Cohen, J. (1992). A power primer. Psychological Bulletin, 112(1), 155-159. doi: 10.1037/0033-2909.112.1.155

Cohen, J., Cohen, P., West, S. G., \& Aiken, L. S. (2003). Applied multiple regression/correlation analysis for the behavioral sciences (3rd ed.). Mahwah, NJ: Erlbaum.

Cribbie, R. A. (2000). Evaluating the importance of individual parameters in structural equation modeling: The need for type I error control. Personality and Individual Differences, 29(3), 567-577. doi: https://doi.org/ 10.1016/S0191-8869(99)00219-6

Crisp, G., \& Cruz, I. (2009). Mentoring college students: A critical review of the literature between 1990 and 2007. Research in Higher Education, 50(6), 525-545. doi: 10.1007/s11162-009-9130-2

Cronbach, L. J., \& Furby, L. (1970). How we should measure "change": Or should we? Psychological Bulletin, 74(1), 68-80. doi: 10.1037/h0029382

Dreher, G. F., \& Ash, R. A. (1990). A comparative-study of mentoring among men and women in managerial, professional, and technical positions. Journal of Applied Psychology, 75(5), 539-546. doi: 10.1037//0021-9010.75.5.539

Eagan, M. K., Jr., Hurtado, S., Chang, M. J., Garcia, G. A., Herrera, F. A., \& Garibay, J. C. (2013). Making a difference in science education: The impact of undergraduate research programs. American Educational Research Journal, 50(4), 683-713. doi: 10.3102/0002831213482038

Eby, L. T., Allen, T. D., Hoffman, B. J., Baranik, L. E., Sauer, J. B., Baldwin, S., .. Evans, S. C. (2013). An interdisciplinary meta-analysis of the potential antecedents, correlates, and consequences of protégé perceptions of mentoring. Psychological Bulletin, 139(2), 441-476. doi: 10.1037/a0029279

Eby, L. T., Rhodes, J. E., \& Allen, T. D. (2007). Definition and evolution of mentoring. In Allen, T. D., \& Eby, L. T. (Eds.), The Blackwell handbook of mentoring: A multiple perspectives approach (pp. 7-20). Oxford, UK: Blackwell.

Enders, C. K. (2010). Applied missing data analysis. New York: Guilford Press.

Enders, C. K. (2011). Analyzing longitudinal data with missing values. Rehabilitation Psychology, 56(4), 267-288. doi: 10.1037/A0025579

Ensher, E. A., \& Murphy, S. E. (1997). Effects of race, gender, perceived similarity, and contact on mentor relationships. Journal of Vocational Behavior, 50(3), 460-481. doi: 10.1006/jvbe.1996.1547

Estrada, M., Burnett, M., Campbell, A. G., Campbell, P. B., Denetclaw, W. F., Gutiérrez, C. G., ... Zavala, M. (2016). Improving underrepresented minority student persistence in STEM. CBE-Life Sciences Education, 15(3), es5. doi: 10.1187/cbe.16-01-0038

Estrada, M., Hernandez, P. R., \& Schultz, P. W. (2018). A longitudinal study of how quality mentorship and research experience integrate underrepresented minorities into STEM careers. CBE-Life Sciences Education, 17(1), ar9. doi: 10.1187/cbe.17-04-0066

Estrada, M., Woodcock, A., Hernandez, P. R., \& Schultz, P. W. (2011). Toward a model of social influence that explains minority student integration into the scientific community. Journal of Educational Psychology, 103(1), 206-222. doi: 10.1037/a0020743 
Fakayode, S. O., Yakubu, M., Adeyeye, O. M., Pollard, D. A., \& Mohammed, A. K. (2014). Promoting undergraduate STEM education at a historically black college and university through research experience. Journal of Chemical Education, 91(5), 662-665. doi: 10.1021/ed400482b

Fuchs, J., Kouyate, A., Kroboth, L., \& McFarland, W. (2016). Growing the pipeline of diverse HIV investigators: The impact of mentored research experiences to engage underrepresented minority students. AIDS and Behavior, 20(suppl 2), 249-257. doi: 10.1007/s10461-016-1392-z

Graham, M. J., Frederick, J., Byars-Winston, A., Hunter, A.-B., \& Handelsman, J. (2013). Increasing persistence of college students in STEM. Science, 341(6153), 1455-1456. doi: 10.1126/science.1240487

Green, S. B., \& Babyak, M. A. (1997). Control of type I errors with multiple tests of constraints in structural equation modeling. Multivariate Behavioral Research, 32(1), 39-51. doi: 10.1207/s15327906mbr3201_2

Hanauer, D. I., \& Dolan, E. L. (2014). The project ownership survey: Measuring differences in scientific inquiry experiences. CBE-Life Sciences Education, 13(1), 149-158. doi: 10.1187/cbe.13-06-0123

Hanauer, D. I., Frederick, J., Fotinakes, B., \& Strobel, S. A. (2012). Linguistic analysis of project ownership for undergraduate research experiences. CBELife Sciences Education, 11(4), 378-385. doi: 10.1187/cbe.12-04-0043

Hanauer, D. I., Graham, M. J., \& Hatfull, G. F. (2016). A measure of college student persistence in the sciences (PITS). CBE-Life Sciences Education, 15(4), ar54. doi: 10.1187/cbe.15-09-0185

Hanauer, D. I., Graham, M. J., SEA-PHAGES, Betancur, L., Bobrownicki, A., Cresawn, S. G., ... Hatfull, G. F. (2017). An inclusive Research Education Community (iREC): Impact of the SEA-PHAGES program on research outcomes and student learning. Proceedings of the National Academy of Sciences. doi: 10.1073/pnas.1718188115

Hathaway, R., Nagda, B., \& Gregerman, S. (2002). The relationship of undergraduate research participation to graduate and professional educational pursuit: An empirical study. Journal of College Student Development, 43(5), 614-631.

Hernandez, P. R., Estrada, M., Woodcock, A., \& Schultz, P. W. (2016). Protégé perceptions of high mentorship quality depend on shared values more than on demographic match. Journal of Experimental Education, 85(3), 450-468. doi: 10.1080/00220973.2016.1246405

Hernandez, P. R., Woodcock, A., Estrada, M., \& Schultz, P. W. (2018). Undergraduate research experiences broaden diversity in the scientific workforce. BioScience, 68(3), 204-211. doi: 10.1093/biosci/bix163

Holdren, J. P., \& Lander, E. (2012). Engage to excel: Producing one million additional college graduates with degrees in science, technology, engineering, and mathematics. Washington, DC: U.S. Government Office of Science and Technology.

Hoyt, C. L., Burnette, J. L., \& Innella, A. N. (2012). I can do that: The impact of implicit theories on leadership role model effectiveness. Personality and Social Psychology Bulletin, 38(2), 257-268. doi:10.1177/0146167211427922

Hu, L., \& Bentler, P. M. (1999). Cutoff criteria for fit indices in covariance structure analysis: Conventional criteria versus new alternatives. Structural Equation Modeling, 6(1), 1-55. doi: 10.1080/10705519909540118

Hunter, A. B., Laursen, S. L., \& Seymour, E. (2007). Becoming a scientist: The role of undergraduate research in students' cognitive, personal, and professional development. Science Education, 91(1), 36-74. doi: 10.1002/Sce.20173

Hurtado, S., Cabrera, N. L., Lin, M. H., Arellano, L., \& Espinosa, L. L. (2009). Diversifying science: Underrepresented student experiences in structured research programs. Research in Higher Education, 50(2), 189-214 doi: 10.1007/s11162-008-9114-7

Jacobi, M. (1991). Mentoring and undergraduate academic success: A literature review. Review of Educational Research, 61(4), 505-532. doi $10.2307 / 1170575$

Judd, C. M., McClelland, G. H., \& Ryan, C. S. (2009). Outliers and ill-mannered error. In Data analysis: A model comparison approach (2nd ed.), (p. 328). New York: Routledge.

Kardash, C. M., \& Edwards, O. V. (2012). Thinking and behaving like scientists: Perceptions of undergraduate science interns and their faculty mentors. Instructional Science, 40(6), 875-899. doi: 10.1007/s11251 -011-9195-0

Kelman, H. C. (2006). Interests, relationships, identities: Three central issues for individuals and groups in negotiating their social environment. Annual Review of Psychology, 57, 1.
Kline, R. B. (2016). Principles and practice of structural equation modeling (4th ed.). New York: Guilford.

Kolber, B. J., Janjic, J. M., Pollock, J. A., \& Tidgewell, K. J. (2016). Summer undergraduate research: A new pipeline for pain clinical practice and research. BMC Medical Education, 16(1), 1-11. doi: 10.1186/s12909-016 $-0648-7$

Kuh, G. D. (2008). High-impact educational practices: What they are, who has access to them, and why they matter. Washington, DC: Association of American Colleges and Universities.

Laursen, S., Hunter, A., Seymour, E., Thiry, H., \& Melton, G. (2010). Undergraduate research in the sciences: Engaging students in real science. San Francisco: Wiley

Lent, R. W., Brown, S. D., \& Hackett, G. (1994). Toward a unifying social cognitive theory of career and academic interest, choice, and performance. Journal of Vocational Behavior, 45(1), 79-122. doi: 10.1006/ jvbe.1994.1027

Linn, M. C., Palmer, E., Baranger, A., Gerard, E., \& Stone, E. (2015). Undergraduate research experiences: Impacts and opportunities. Science, 347(6222), 12617571-12617576. doi: 10.1126/science.1261757

Little, R. J. A. (1988). A test of missing completely at random for multivariate data with missing values. Journal of the American Statistical Association 83(404), 1198-1202. doi: 10.1080/01621459.1988.10478722

Lockwood, P. (2006). "Someone like me can be successful": Do college students need same-sex gender role models? Psychology of Women Quarterly, 30(1), 36-46. doi: 10.1111/j.1471-6402.2006.00260.x

Lockwood, P., Jordan, C. H., \& Kunda, Z. (2002). Motivation by positive or negative role models: Regulatory focus determines who will best inspire us. Journal of Personality and Social Psychology, 83(4), 854-864. doi: 10.1037/0022-3514.83.4.854

Lockwood, P., \& Kunda, Z. (1997). Superstars and me: Predicting the impact of role models on the self. Journal of Personality and Social Psychology, 73(1), 91-103. doi: 10.1037/0022-3514.73.1.91

Lockwood, P., \& Kunda, Z. (1999). Increasing the salience of one's best selves can undermine inspiration by outstanding role models. Journal of Personality and Social Psychology, 76(2), 214-228. doi: 10.1037/0022 $-3514.76 .2 .214$

Lopatto, D. (2003). The essential features of undergraduate research Retrieved May 12, 2016, from www.cur.org/download.aspx?id=529

Lopatto, D. (2004). Survey of undergraduate research experiences (SURE): First findings. Cell Biology Education, 3(4), 270-277. doi: 10.1187/cbe.04 $-07-0045$

Lopatto, D. (2007). Undergraduate research experiences support science career decisions and active learning. CBE-Life Sciences Education, 6(4), 297-306. doi: 10.1187/cbe.07-06-0039

MacKinnon, D. P., Fairchild, A. J., \& Fritz, M. S. (2007). Mediation analysis Annual Review of Psychology, 58, 593-614. doi: 10.1146/annurev.psych 58.110405.085542

Maxwell, S. E. (1998). Longitudinal designs in randomized group comparisons: When will intermediate observations increase statistical power? Psychological Methods, 3(3), 275-290. doi: 10.1037/1082-989X.3.3.275

Maxwell, S. E., \& Delaney, H. D. (2004). Designing experiments and analyzing data: A model comparison perspective. New York: Psychology Press.

Merolla, D. M., \& Serpe, R. T. (2013). STEM enrichment programs and graduate school matriculation: The role of science identity salience. Social Psychology of Education, 16(4), 575-597. doi: 10.1007/s11218 -013-9233-7

Mervis, J. (2016). Genuine research keeps students in science. Science 352(6291), 1266-1266.

Muthén, B. O., \& Muthén, L. K. (1998-2017). Mplus User's Guide (Version 8.0) Los Angeles: Muthén \& Muthén.

Nagda, B. A., Gregerman, S. R., Jonides, J., Hippel, W., \& Lerner, J. S. (1998). Undergraduate student-faculty research partnerships affect student retention. Review of Higher Education, 22(1), 55-72.

National Academies of Sciences, Engineering, and Medicine. (2017). In Gentile, J., Brenner, K., \& Stephens, A. (Eds.), Undergraduate research experiences for STEM students: Successes, challenges, and opportunities (2017). Washington, DC.

National Academy of Sciences, National Academy of Engineering, and Institute of Medicine. (2007). Rising above the gathering storm: Energizing 
and employing America for a brighter economic future. Washington, DC National Academies Press.

Olson, S., \& Riordan, D. G. (2012). Engage to excel: Producing one million additional college graduates with degrees in science, technology, engineering, and mathematics. Washington, DC: U.S. Government Office of Science and Technology.

Paglis, L., Green, S., \& Bauer, T. (2006). Does adviser mentoring add value? A longitudinal study of mentoring and doctoral student outcomes. Research in Higher Education, 47(4), 451-476. doi: 10.1007/s11162-005 -9003-2

Pfund, C., Byars-Winston, A., Branchaw, J., Hurtado, S., \& Eagan, K. (2016). Defining attributes and metrics of effective research mentoring relationships. AIDS and Behavior, 20, S238-S248. doi: 10.1007/s10461-016-1384-z

Pfund, C., Pribbenow, C. M., Branchaw, J., Lauffer, S. M., \& Handelsman, J. (2006). The merits of training mentors. Science, 311(5760), 473-474. doi: 10.1126/science.1123806

Raudenbush, S. W., \& Bryk, A. S. (2002). Hierarchical linear models: Applications and data analysis methods (2nd ed.). Newbury Park, CA: Sage.

Robnett, R. D., Chemers, M. M., \& Zurbriggen, E. L. (2015). Longitudinal associations among undergraduates' research experience, self-efficacy, and identity. Journal of Research in Science Teaching, 52(6), 847-867. doi: 10.1002/tea.21221

Rodenbusch, S., Hernandez, P. R., Simmons, S. L., \& Dolan, E. L. (2016). Early engagement in course-based research increases graduation rates and completion of science, engineering, and mathematics degrees. CBELife Sciences Education, 15(2), ar20. doi: 10.1187/cbe.16-03-0117

Russell, S. H., Hancock, M. P., \& McCullough, J. (2007). Benefits of undergraduate research experiences. Science, 316(5824), 548-549. doi 10.1126/science.1140384

Sadler, T. D., Burgin, S., McKinney, L., \& Ponjuan, L. (2010). Learning science through research apprenticeships: A critical review of the literature. Journal of Research in Science Teaching, 47(3), 235-256. doi: 10.1002/Tea.20326

Schultz, P. W., Hernandez, P. R., Woodcock, A., Estrada, M., Chance, R. C. Aguilar, M., \& Serpe, R. T. (2011). Patching the pipeline: Reducing educational disparities in the sciences through minority training programs. Educational Evaluation and Policy Analysis, 33(1), 95-114. doi: 10.3102/ 0162373710392371

Seymour, E., Hunter, A. B., Laursen, S. L., \& Deantoni, T. (2004). Establishing the benefits of research experiences for undergraduates in the sciences:
First findings from a three-year study. Science Education, 88(4), 493534. doi: 10.1002/Sce.10131

Shadish, W., Cook, T., \& Campbell, D. (2002). Experimental and quasi-experimental designs for generalized causal inference. Boston: Houghton Mifflin

Shin, J. E. L., Levy, S. R., \& London, B. (2016). Effects of role model exposure on stem and non-stem student engagement. Journal of Applied Social Psychology, 46(7), 410-427. doi: 10.1111/jasp.12371

Shrout, P. E., \& Bolger, N. (2002). Mediation in experimental and nonexperimental studies: New procedures and recommendations. Psychological Methods, 7(4), 422-455. doi: 10.1037/1082-989X.7.4.422

Thiry, H., \& Laursen, S. L. (2011). The role of student-advisor interactions in apprenticing undergraduate researchers into a scientific community of practice. Journal of Science Education and Technology, 20(6), 771-784. doi: 10.1007/s10956-010-9271-2

Thiry, H., Laursen, S. L., \& Hunter, A.-B. (2011). What experiences help students become scientists? A comparative study of research and other sources of personal and professional gains for STEM undergraduates. Journal of Higher Education, 82(4), 357-388.

Thiry, H., Weston, T. J., Laursen, S. L., \& Hunter, A.-B. (2012). The benefits of multi-year research experiences: Differences in novice and experienced students' reported gains from undergraduate research. CBE-Life Sciences Education, 11(3), 260-272. doi: 10.1187/cbe.11-11-0098

Venter, A., Maxwell, S. E., \& Bolig, E. (2002). Power in randomized group comparisons: The value of adding a single intermediate time point to a traditional pretest-posttest design. Psychological Methods, 7(2), 194209. doi: 10.1037//1082-989x.7.2.194

Wang, M. T., \& Degol, J. (2013). Motivational pathways to STEM career choices: Using expectancy-value perspective to understand individual and gender differences in STEM fields. Developmental Review, 33(4), 304340.

Woodcock, A., Hernandez, P. R., \& Schultz, P. W. (2015). Diversifying science: Intervention programs moderate the effect of stereotype threat on motivation and career choice. Social Psychological and Personality Science, 7(2), 184-192. doi: 10.1177/1948550615608401 